\title{
The second case of Noonan Syndrome: The association with unique multiple Cardiac Defects
}

\section{Aamir Jalal Al Mosawi}

Advisor in Pediatrics and Pediatric Psychiatry Children Teaching Hospital of Baghdad Medical City, Head, Iraq Headquarter of Copernicus Scientists International Panel Baghdad, Iraq

Corresponding author: Aamir Jalal Al Mosawi, Advisor in Pediatrics and Pediatric Psychiatry Children Teaching Hospital of Baghdad Medical City, Head, Iraq Headquarter of Copernicus Scientists International Panel Baghdad, Iraq.

Received date: February 13, 2020; Accepted date: February 26, 2020; Published date: March 03, 2020

Citation: Al Mosawi AJ. (2020) The Second Case Of Noonan Syndrome: The Association With Unique Multiple Cardiac Defects. Cardiology Research and Reports, 2(1): Doi: 10.31579/ 2692-9759/004

Copyright: () 2020 Aamir Jalal Al Mosawi, This is an open access article distributed under the Creative Commons Attribution License, which permits unrestricted use, distribution, and reproduction in any medium, provided the original work is properly cited.

\begin{abstract}
Background: Noonan syndrome is a heterogeneous congenital disorder that can occur sporadically or inherited as an autosomal dominant disorder. It is characterized by a wide spectrum of phenotypic abnormalities that vary greatly in range and severity, and two patients with Noonan syndrome may have two different characteristic features. In many patients the syndrome characterized by craniofacial abnormalities including low set ears, hypertelorism, congenital heart defect, short stature, and undescended testes. Although pulmonary stenosis is the commonly associated congenital cardiac defects, a variety of cardiac defects may occur in this syndrome. Atrial septal defect, and patent ductus arteriosus are other well-recognized cardiac defects of this syndrome. The diagnosis of Noonan syndrome is entirely clinical as there is no specific diagnostic available

Materials and methods: A ten month old boy who was referred to the pediatric neuropsychiatric clinic of the Children Teaching Hospital of Baghdad Medical City because of developmental delay associated with multiple congenital abnormalities was studied.

Results: The boy had growth and developmental retardation, low set ears, hypertelorism, and smooth philtrum, undescended testes. Echocardiography showed interatrial septum, small atrial septal defect and closing patent ductus arteriosus.

Conclusion: Noonan syndrome was previously reported only in one girl from Iraq. The first Iraqi boy with Noonan syndrome is reported in association with unique cardiac defects. The previously reported case and the case in this deport demonstrates the variability of the phenotype of this syndrome.
\end{abstract}

Keywords: noonan syndrome; cardiac defects; interatrial septum; iraq.

\section{Introduction}

Noonan syndrome is a heterogeneous congenital disorder that can occur sporadically or inherited as an autosomal dominant disorder. It is characterized by a wide spectrum of phenotypic abnormalities that vary greatly in range and severity, and two patients with Noonan syndrome may have two different characteristic features. In many patients the syndrome characterized by craniofacial abnormalities including low set ears, hypertelorism, congenital heart defect, short stature, and undescended testes. Although pulmonary stenosis is the commonly associated congenital cardiac defects, a variety of cardiac defects may occur in this syndrome. Atrial septal defect, and patent ductus arteriosus are other well-recognized cardiac defects of this syndrome. The diagnosis of Noonan syndrome is entirely clinical as there is no specific diagnostic available [1-5].

\section{Materials and methods}

A ten month old boy who was referred to the pediatric neuropsychiatric clinic of the Children Teaching Hospital of Baghdad Medical City because of developmental delay associated with multiple congenital abnormalities was studied.

\section{Results}

The boy was experiencing growth and developmental delay and was unable to sit. He had facial dysmorphic features consisting of low set ears, hypertelorism, and smooth philtrum (Figure-1). Examination of the heart suggested the presence of congenital heart disease and his testes were not palpable in the scrotum. Echocardiography showed interatrial septum, small atrial septal defect and closing patent ductus arteriosus. Abdominal 
ultrasound showed ectopic intra-abdominal testes located at the inlet of the inguinal, and both testes measures $10 \mathrm{~mm}$ in diameter (Figure-2). Chromosomal analysis showed normal female karyotype.
Parents were consanguineous and family history was negative for similar condition.

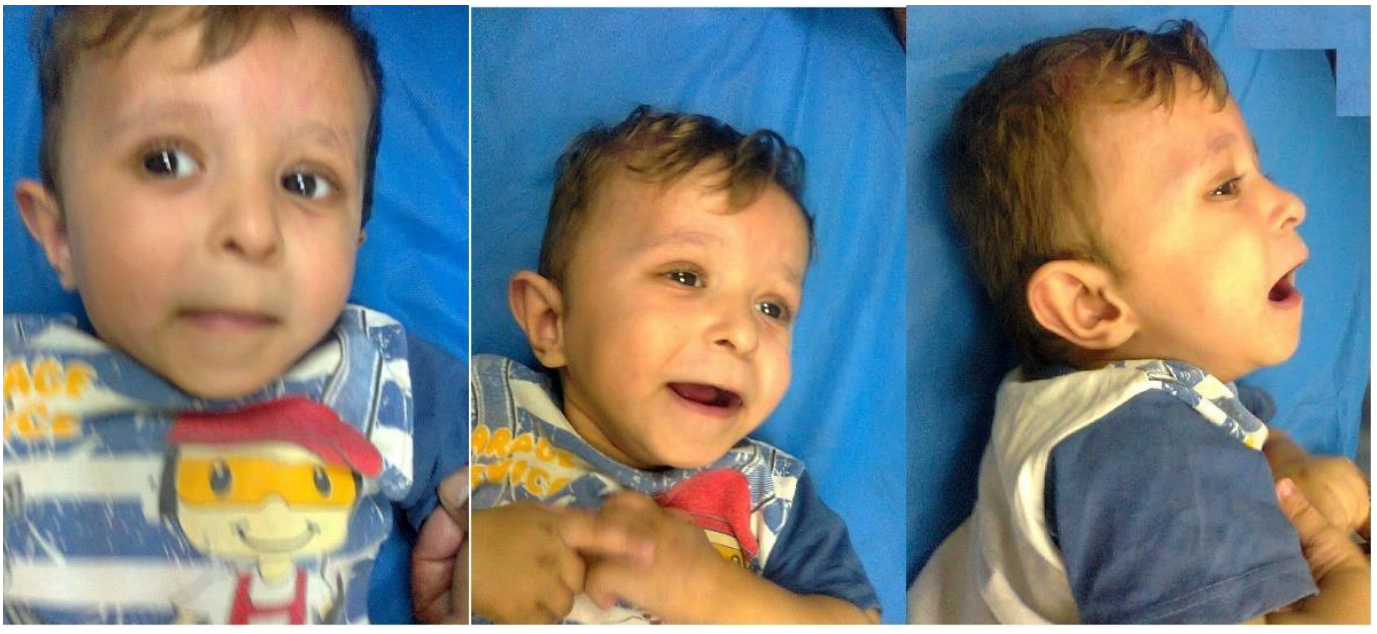

Figure-1: The infant had facial dysmorphic features consisting of low set ears, hypertelorism, and smooth philtrum

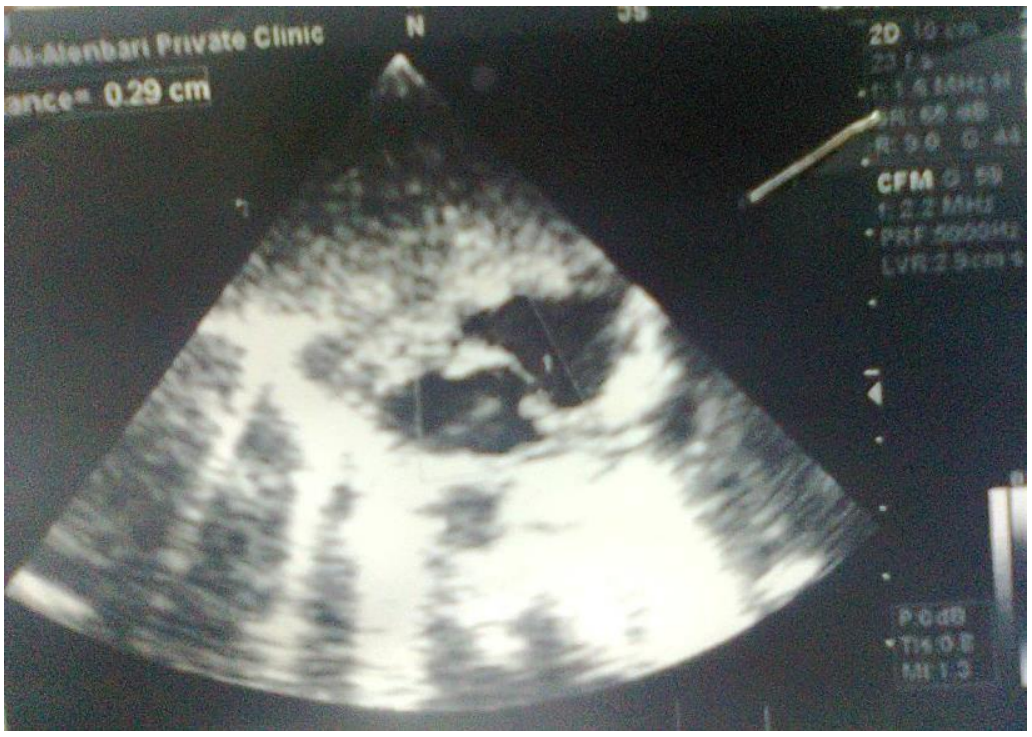

Figure-2: Abdominal ultrasound showed ectopic intra-abdominal testes located at the inlet of the inguinal, and both testes measures 10 mm in diameter

\section{Discussion}

During the 1940s, 1950s, and early 1960s Noonan syndrome was considered to be Turner syndrome occurring in males [6-11]. However, at the meeting of the Mid-Western Society for Pediatric Research in 1962, Jacqueline A. Noonan (Figure-3) presented nine patients who had growth retardation, hypertelorism syndrome of valvular pulmonary stenosis and other congenital abnormalities. In 1968, Jacqueline A. Noonan published reporting 19 patients including males and females [1, 2]. In 1971, Hellebusch called the condition Noonan syndrome [12]. Noonan syndrome was previously reported only in one girl from
Iraq. She had also a sporadic form of Noonan with predominant cerebral manifestations and without congenital heart defect [5]. The previously reported case and the case in this deport demonstrates the variability of the phenotype of this syndrome.

\section{Conclusion}

The first Iraqi boy with Noonan syndrome is reported in association with unique cardiac defects. 


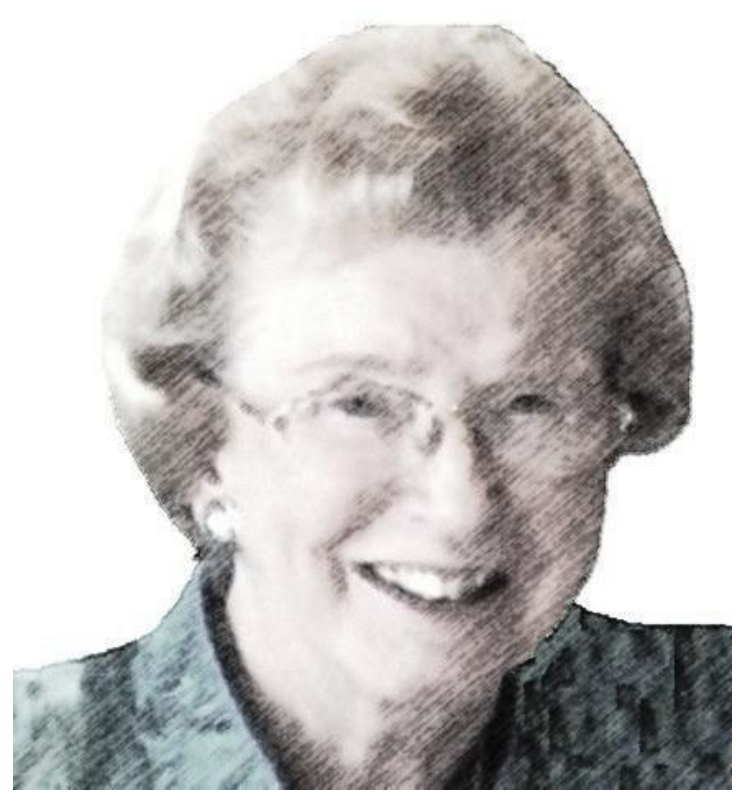

Figure-3: Jacqueline Noonan, a pediatric cardiologist at the University of Iowa

\section{Acknowledgement}

1-The author would to express his gratitude for the parents of the patient who accepted publishing his photos.

2-The author has the copyright of the sketch in figure-3.

\section{References}

1. Noonan JA, Ehmke DA. Associated noncardiac malformations in children with congenital heart disease. Midwest Soc Pediatr Res 1063; 63: 468-70.

2. Noonan JA. (1968). Hypertelorism with Turner phenotype: a new syndrome with associated congenital heart disease. Am J Dis Child, 116(4):373-380.

3. Collins E, Turner G. (1973). The Noonan syndrome: a review of the clinical and genetic features of 27 cases. J Pediatr, 83(6):941-950.

4. Digilio M, Marino B. (2001) Clinical manifestations of Noonan syndrome. Images Paediatr Cardiol, 3(2):19-30.

5. Al-Mosawi AJ. (2019). Noonan syndrome with CT-scan evidence of brain atrophy and ventriculomegaly. Journal of Clinical Research and Reports, 1(1):003.

6. Dorff GB, Appelman DH, Liveson A. (1948). Turner's syndrome in the male; report of a case showing defects such as short stature, sexual underdevelopment, webbed neck and various other congenital defects without any increased urinary pituitary gonadotropins. Arch Pediatr, 65(10):555-561.

7. Reforzo-Membrives J, Trabucco A, EscardO F. (1949). A case of rudimentary testes, delayed growth and congenital malformations; Turner's syndrome in a male. J Clin Endocrinol Metab, 9(12):1333-1348.

8. Grivaux M. (1950). Turner's syndrome in males. Sem Hop, 26(33):1558-9.

9. James T. (1952). Turner's syndrome in a male infant. Edinb Med J, 59(7):344-54.

10. Krauland-Steinbereithner F, Spiel W. (1953). A case of genital dwarfism; Turner syndrome in man. Dtsch Arch Klin Med, 200(4):490-6.

11. Fraccaro M, Ikkos D, Lindsten J, Luft R, Tillinger KG. (1961). Testicular germinal dysgenesis (male Turner's syndrome). Report of a case with chromosomal studies and review of the literature. Acta Endocrinol (Copenh), 36:98-114.

12. Hellebusch AA. (1971). Noonan syndrome with bilateral ureteral ectopia. J Pediatr Surg, 6(4):490. PMID: 5563894.

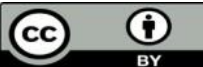

This work is licensed under Creative Commons Attribution 4.0 License

To Submit Your Article Click Here: Submit Article
Ready to submit your research? Choose Auctores and benefit from:

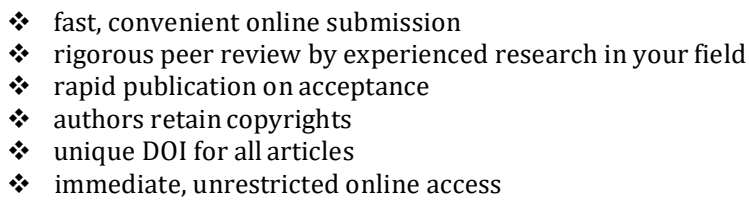

At Auctores, research is always in progress.

Learn more https://www.auctoresonline.org/journals/cardiology-research-and-reports 